\title{
Foot hexadactyly, social implications and management in the African setting: Case report
}

\author{
Komla Sena Amouzou¹, Elodie Lucrece Joyce Malonga-Loukoula², Tete Edem Kouevi-Koko', \\ Batarabadja Bakriga ${ }^{1}$, Anani Abalo ${ }^{1}$ \\ ${ }^{1}$ Department of Traumatology, Orthopedic and Reconstructive Surgery, University of Lome, Teaching Hospital Sylvanus \\ Olympio, Lomé Togo, ${ }^{2}$ Hassan II University, Casablanca, Morocco. E- mail: alain.amouzou@gmail.com \\ Received: 14th July 2017, Accepted: 17th September 2017
}

\begin{abstract}
SUMMARY: Amouzou KS, Malonga-Loukoula ELJ, Kouevi-Koko TE, Bakriga B, Abalo A. Foot hexadactyly, social implications and management in the African setting: Case report. Turk J Pediatr 2018; 60: 453-455.

Hexadactyly of the foot, an abnormal congenital condition presenting as eight toes, is a rare malformation. We report the case of a ten-year-old girl, admitted to our orthopedic and reconstructive surgery department for a preaxial hexadactyly. The girl was abandoned by her parents at birth and stopped school early due to stigmatization. The goals of the surgical procedure were: social reintegration, gait improvement, ability to wear shoes comfortably, and improved appearance of the foot. The surgery was a medial resection of the supernumerary toes.
\end{abstract}

Key words: polydactyly, foot malformation, congenital malformation, Africa.

Polydactyly of the foot is a common malformation. The condition is frequent among black populations, and commonly presents as supernumerary one or two toes. ${ }^{1,2}$ Hexadactyly is rarer. It can appear alone or as a part of a syndromic malformation often described as the mirror foot. ${ }^{3-6}$ Despite recent advances in the understanding of the mechanism underlying the occurrence of these malformations based on animal experimentations, the pathophysiology of polydactyly is still a matter of debate. Treatment modalities have been described in individual cases, and there exist no real guidelines. To the best of our knowledge, this is the first description of such a case in our country. Previously-published cases did not address the added complexities of treating such cases within the particular environment of Africa, especially in remote places where cultural biases could overcome scientific understanding of such malformations.

We report this rare case, its social implications in our setting, and early results of the surgical procedure.

\section{Case Report}

A 10-year-old girl was admitted to our surgical department for a congenital malformation of her left foot. The malformation was characterized by the presence of eight toes on the left foot. The girl was abandoned by her parents at birth, and raised by another family. These circumstances made it impossible to collect the history of pregnancy or assess any familial history of polydactyly. Consent has been given by the tutor for treatment and publication of the case.

The girl was unable to wear shoes on the deformed foot. Her deformity had profound psychological and social deleterious effects on her. She was embarrassed to walk barefoot in public causing her to spend much time indoors and the level of ridicule and bullying by her peers made her drop out of school. She suffered from stigmatization and mocked as an abnormal person.

Clinical examination found a large left foot with preaxial hexadactyly (Fig 1). Walking was possible but required claudication. No other malformation or medical concern was observed during the physical examination. Left foot $\mathrm{X}$-ray showed presence of seven metatarsals. Lower ends of the tibia and fibula, visible on the X-ray were normal (Fig 2).

Surgical procedure was a resection of the three 
medial rays (Fig 3). The foot was kept in a bandage to prevent a varus deviation of the big toe. After 10 post-operative days, the wound healed but the bandage was kept to for three more weeks. Unfortunately, the girl was lost to follow-up screening after hospital discharge.

\section{Discussion}

Hexadactyly is a rare anomaly that can be preaxial, postaxial, or central. The hallux may

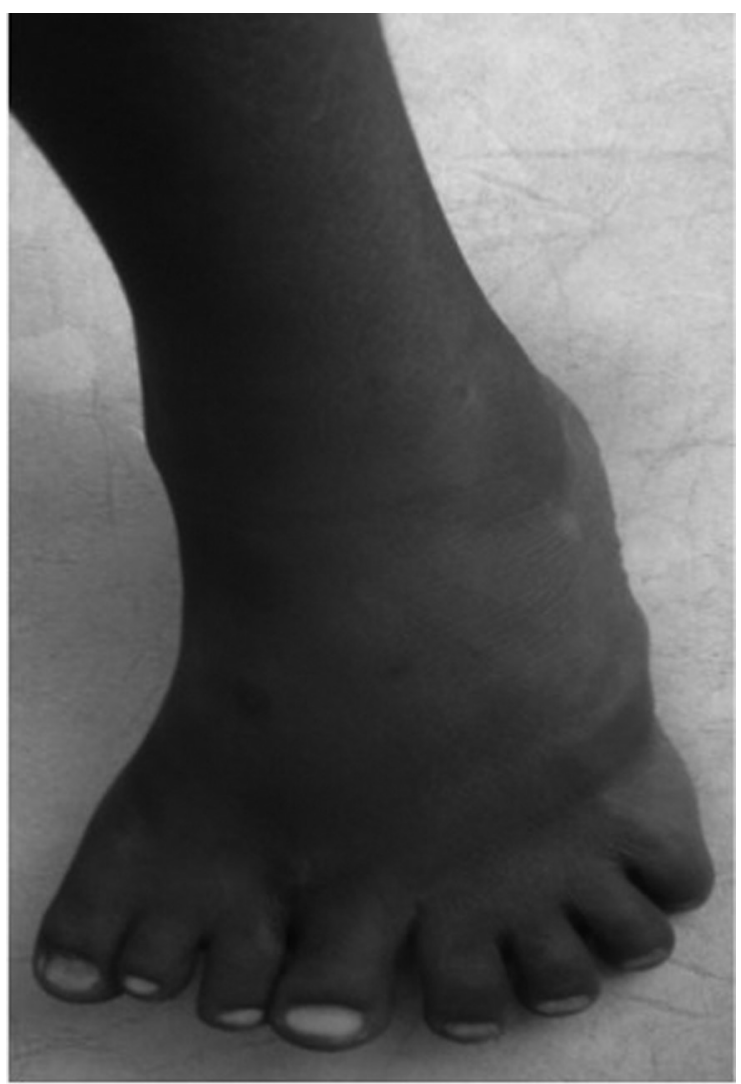

Fig. 1. Foot pre-axial hexadactyly.
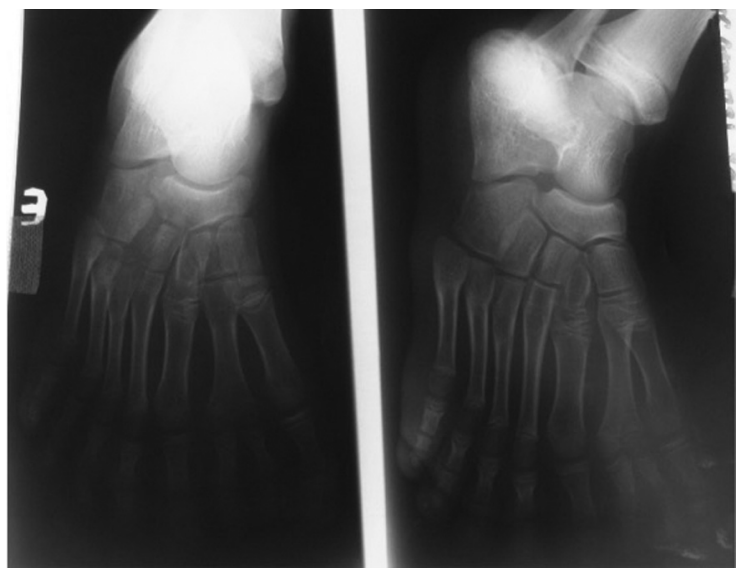

Fig. 2. X-Ray of the foot and ankle. be absent or present centrally located, unique or duplicated.1,4,6-10 In our case, the polydactyly was pre-axial. The tibia and fibula were clinically and radiologically normal. Therefore, this case may not be considered a mirror foot. As reported in many publications $4,6,7,11$, the pathophysiological explanation is based on the Zone of Polarizing Activity (ZPA), a group of mesenchymal cells located in the embryologic limb bud. The ZPA is responsible of digit patterning during embryo development. ZPA morphogen, the Sonic Hedgehog (Shh), and the regulatory sequence (ZRS) of the ZPA are all involved in the occurrence of the malformation. A positioning error, duplication of the ZPA or abnormal signal from the Shh, abnormal control by ZPA-ZRS are thought to be the conditions leading to the appearance of an abnormal number of toes. 4,9,11,12 An increased activation of Shh feedback network and growth, lead to preaxial polydactyly. ${ }^{11}$

Genetic implications have been reported. Hwang $\mathrm{K}$ et al. $^{2}$ analyzed two families affected in four generations and two generations by polydactyly. They concluded that inheritance of foot polydactyly has a major genetic implication but other undetermined factors may also play important roles.

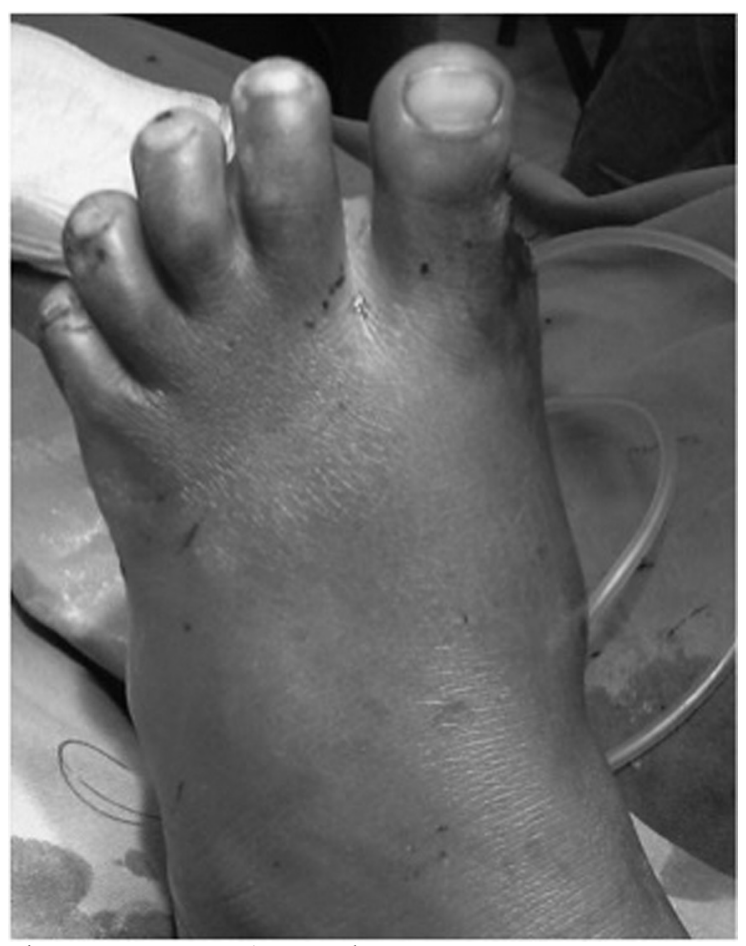

Fig. 3. Post-operative result. 
Many procedures have been reported for surgical cure of minor cases. $5,7,10,13,14$ Surgical removal of supra numeric toes aims to improve walking function, facilitating shoe wearing, and improving cosmetic appearance. In addition to these generally-accepted indications, we added social reintegration in our case. In the African setting, congenital anomalies are often considered as manifestation of the supernatural, or the result of divine punishment for a serious misconduct of the parents. Indeed, malformations in children usually cause marital breakdowns and/or abandonment of children. In some remote places, far from the modern civilization, some deformed children have their life taken as atonement for perceived sins. So, many children do not have access to medical treatment. These are the socio-economic circumstances preventing the girl from getting her deformity corrected prior to age 10 .

Surgical resection of the medial rays, preferably by a transverse medial incision, has the advantage of not jeopardizing the vascularization of the plantar and dorsal soft tissue flaps as reported by El-Shalzy $\mathrm{M}^{7}$. A case reported by Skoll PJ et al. ${ }^{5}$ in South Africa presented postoperative varus deviation of the Hallux. To avoid this late complication, some authors have advocated intraosseous needling of the radius of the hallux. $5,7,10$ We think this practice could harm the growth plates, or be a source of infection especially in African children. An external splinting of the first ray as reported by Bonnet $\mathrm{F}$ et $\mathrm{al}^{6}{ }^{6}$ and El-Shazly $\mathrm{M}^{7}$ is for us, a more reliable option. Follow up is important to see the efficiency of such methods. Unfortunately, this has not been possible in our case as the girl was taken far back to her village and probably satisfied with what she obtained thus, did not come back for further visits.

\section{Acknowledgment}

Authors are thankful to Mr. Atchu Attoh who geratly contributed to English editing of the article.

\section{REFERENCES}

1. Castilla EE, Lugarinho Da Fonseca R, da Graca Dutra M, Bermejo E, Cuevas L, Martinez-Frias ML. Epidemiological analysis of rare polydactylies. Am J Med Genet 1996; 65: 295-303.2

2. Hwang K, Kim ET, Lee SI. Foot polydactyly and polysyndactyly: Genetic implications in two families. J Foot Ankle Surg 2005; 44: 473-477.

3. Laurin CA, Favreau JC, Labelle P. Bilateral absence of the radius and tibia with bilateral reduplication of the ulna and fibula. A case report. J Bone Joint Surg Am 1964; 46: 137-142.

4. Sandrow RE, Sullivan PD, Steel HH. Hereditary ulnar and fibular dimelia with peculiar facies. A case report. J Bone Joint Surg Am 1970; 52: 367-370.

5. Skoll PJ, Silfen R, Hudson DA, Bloch CE. Mirror foot. Plast Reconstr Surg 2000; 105: 2086-2088.

6. Bonnet F, Garrido I, Haddad R, Pavy B, Mitrofanoff M. Complex polydactyly of the limbs: Mirror foot. Report of two cases and review of literature. Ann Chir Plast Esthet 2005; 50: 323-327.

7. El-Shazly M. An eight-toed foot: A rare pedal polydactyly. J Foot Ankle Surg 2007; 46: 207-209.

8. Al-Qattan MM, Hashem FK, Al Malaq A. An unusual case of preaxial polydactyly of the hands and feet: A case report. J Hand Surg Am 2002; 27: 498-502.

9. Dan U, Nayek K, Ghosh TN, Akhtar S. Complete tibial aplasia with preaxial polydactyly: A kindred of affected individuals in three generations. J Anat Soc India 2010; 59: 44-47.

10. Wang HJ, Cheng LF, Tung YM, Chen TM. Centraltype eight-toed polydactyly associated with ipsilateral complex renogluteal agenesis: A case report with 8 years' follow-up. J Pediatr Surg 1996; 31: 444-446.

11. Johnson EJ, Neely DM, Dunn IC, Davey MG. Direct functional consequences of ZRS enhancer mutation combine with secondary long range $\mathrm{SHH}$ signalling effects to cause preaxial polydactyly. Dev Biol 2014; 392: 209-220.

12. Han SH, Cho JH, Lee YS. An unusual case of postaxial polydactyly of the foot treated by metatarsal transfer. J Foot Ankle Surg 2014; 53: 59-61.

13. Morley SE, Smith PJ. Polydactyly of the feet in children: Suggestions for surgical management. Br J Plast Surg 2001; 54: 34-38.

14. Lui TH. Correction of postaxial metatarsal polydactyly of the foot by percutaneous ray amputation and osteotomy. J Foot Ankle Surg 2013; 52: 128-131. 